\title{
REGIÃO DOS VALES - RS: OBSERVANDO A DISPERSÃO TERRITORIAL DA PANDEMIA DA COVID-19
}

\author{
VALES REGION - RS: AN OBSERVATION OF THE \\ TERRITORIAL DISPERSION OF COVID-19 PANDEMIC
}

\section{Rosmari Terezinha Cazarotto}

Doutora em Geografia pela Universidade Federal do Rio Grande do Sul (Porto Alegre/Brasil).

Pesquisadora do CNPq e Professora na Universidade do Vale do Taquari (Lajeado/Brasil).

E-mail: rosmari.cazarotto@univates.br

\section{Rogerio Leandro Lima da Silveira}

Doutor em Geografia pela Universidade Federal de Santa Catarina (Florianópolis/Brasil). Pesquisador do CNPq e Professor do Programa de Pós-Graduação em Desenvolvimento Regional, da Universidade de Santa Cruz do Sul (Santa Cruz do Sul/Brasil).

E-mail: rlls@unisc.br

\section{Carolina Rezende Faccin}

Doutoranda em Planejamento Urbano e Regional pela Universidade Federal do Rio Grande do Sul (Porto Alegre/Brasil).

E-mail: faccincarolina@gmail.com

\section{Helena de Moura Vogt}

Mestra em Desenvolvimento Regional pela Universidade de Santa Cruz do Sul (Santa Cruz do Sul/Brasil).

Arquiteta e Urbanista pela Pontifícia Universidade Católica do Rio Grande do Sul (Porto Alegre/Brasil).

E-mail: helenamvogt@gmail.com

Recebido em: 13 de janeiro de 2021

Aprovado em: 28 de março de 2021

Sistema de Avaliação: Double Blind Review

RGD | v. 18 | n. 2 | p. 56-71 | mai./ago. 2021

DOI: https://doi.org/10.25112/rgd.v18i2.2484 


\section{RESUMO}

Aborda-se neste artigo o padrão espacial da dinâmica de dispersão territorial da Covid-19 na região dos Vales-RS. De abordagem qualitativa, com o uso de dados secundários coletados junto a órgãos oficiais, no período de 20 de março a 17 de julho de 2020, relativos à dispersão da pandemia da Covid-19 na região, busca-se identificar possíveis relações dessa dinâmica com a estrutura e funcionamento da rede urbana regional, com a estrutura econômica e a divisão territorial do trabalho regional. Ademais, foram consideradas as interações espaciais intrarregionais comandadas pelos principais centros econômicos e de serviços da região dos Vales, as cidades médias de Lajeado e de Santa Cruz do Sul. Observou-se que a dinâmica de dispersão territorial da Covid-19 na região dos Vales-RS apresenta características semelhantes ao verificado em outras regiões e cidades no Brasil e no exterior, mas também revela particularidades entre as sub-regiões que lhe constituem, relacionadas aos usos do território.

Palavras-chave: Região dos Vales. Dispersão territorial da Covid-19. Rede urbana regional.

\section{ABSTRACT}

This article focuses on the spatial pattern of the territorial dispersion dynamics of Covid-19 in the ValesRS region. With a qualitative approach and using secondary data collected from official agencies, from March 20 to July 17, 2020, related to the dispersion of the Covid-19 pandemic in the region, the article seeks to identify possible relationships between this dynamics and the structure and functioning of the regional urban network, with the economic structure and the territorial division of regional labor. In addition, intraregional spatial interactions led by the main economic and service centers in the Valleys region, the medium cities of Lajeado and Santa Cruz do Sul were considered. It was observed that the dynamics of territorial dispersion of Covid-19 in the Valleys region, in Rio Grande do Sul, presents characteristics similar to those observed in other regions and cities in Brazil and abroad, but it also reveals particularities among the sub-regions that constitute it, related to the uses of the territory.

Keywords: Vales region. Territorial dispersion of Covid-19. Regional urban network. 


\section{INTRODUÇÃO}

A Covid-19 é uma doença infecciosa causada pelo novo coronavírus SARS-CoV-2. Considerada uma pandemia desde o decreto da Organização Mundial da Saúde (OMS) do dia 11 de março (WHO, 2020), surgiu na cidade de Wuhan, na China e chegou ao Brasil em fevereiro de 2020 (BRASIL, 2020) e, no mês seguinte, no dia 10 de março (SES-RS, 2020a), alcançou o Rio Grande do Sul.

A primeira vez que autoridades chinesas reportaram à OMS o aparecimento de casos humanos de pneumonia de causa desconhecida, foi em 31 de dezembro de 2019. Desde então, rapidamente se espalhou por outros países e continentes, geralmente a partir dos grandes centros urbanos, e aos poucos foi se dispersando por cidades médias e pequenas avançando para o interior dos territórios.

Este fenômeno está associado às condições do meio técnico-científico-informacional que acelera os fluxos e aproxima os lugares, facilitando a circulação do vírus diante da globalização da economia. A capacidade da mobilidade humana por rotas globais facilitou a circulação do novo Coronavírus SARS-Cov-2. Os primeiros contaminados foram aqueles pertencentes às classes de alta renda, por terem condições financeiras para viajar por distintos hemisférios e continentes, e posteriormente se disseminando entre as classes mais baixas e vulneráveis. Nos termos de Santos (2006), a fluidez da dispersão se deu primeiramente nos territórios (globais) com maiores densidades técnicas, dos equipamentos instalados, os chamados espaços luminosos, e, na sequência, pessoas que se movimentam de espaços menos providos ou até desprovidos destes equipamentos, em busca de empregos e serviços, propagaram o vírus nos espaços opacos.

A região dos Vales, constituída pelas sub-regiões contíguas do Vale do Rio Pardo e do Vale do Taquari, no Rio Grande do Sul, teve os primeiros casos confirmados no dia 21 de março, nos municípios de Lajeado e Estrela (RIBEIRO, 2020), a partir de pessoas que retornaram de viagens à Europa e de um Cruzeiro marítimo pela costa brasileira.

Diante desse contexto, a equipe do Observatório do Desenvolvimento Regional, ligado ao Programa de Pós-Graduação em Desenvolvimento Regional, da Universidade de Santa Cruz do Sul, decidiu criar o projeto de extensão ObservaDR/Covid-19 com o propósito de oferecer ao público dados secundários e mapas temáticos, com notas e informações científicas, sobre variáveis sociais, demográficas, de infraestrutura e saúde da população nos domicilios dos bairros dos municípios de Santa Cruz do Sul e de Venâncio Aires, e dados e mapas regionais sobre a dinâmica territorial de propagação do vírus no Rio Grande do Sul e na região dos Vales. O objetivo do projeto é o de produzir informações científicas que possam informar e conscientizar a sociedade regional, bem como servir de apoio à tomada de decisões por 
parte dos gestores públicos municipais e lideranças regionais nas ações de prevenção, controle, mitigação e combate à Covid-19 no território regional.

Neste artigo, que apresenta parte dos resultados obtidos neste projeto, busca-se identificar e analisar a dinâmica territorial do novo Coronavírus no território regional, notadamente nas escalas regional e. Também se analisa as relações entre o padrão espacial e a dinâmica de dispersão no território com o funcionamento da rede urbana e com a centralidade e funções das cidades médias de Lajeado e Santa Cruz do Sul, principais centros econômicos e de serviços da região dos Vales.

Levantar dados sobre a realidade em que se vive é importante para, a partir dela, fornecer informações úteis ao planejamento de ações e à tomada de decisões para a prevenção e combate à pandemia ocasionada pela expansão do Coronavírus, bem como oferecer informações científicas para o conjunto da sociedade.

Para Santos (2007), a ideia de escala geográfica está associada à totalidade do mundo e nos conduz a uma análise do espaço geográfico nas suas dimensões local, regional, nacional e global, enquanto um conjunto indissociável de sistema de objetos e sistema de ações. Um conjunto de fixos e fluxos que interagem no espaço geográfico. Os objetos contidos no espaço dizem respeito às formas, já as ações, que se realizam em relação e por meio dos objetos, dizem respeito às funções e resultam de e expressam práticas sociais. Neste sentido a territorialização do espaço é processo e produto das relações sociais. 0 território é entendido enquanto um espaço produzido, vivido e apropriado pelo uso e, determinado pelas distintas funções espaciais e diferentes usos que apresenta. É o uso do território que faz dele objeto de análise.

Para compreender a dispersão da Covid-19 pelo território, as contribuições de Milton Santos orientam para a análise dos desdobramentos oriundos das diferentes funções e usos do espaço, pois a apropriação social do espaço produz territórios e territorialidades propícias à disseminação de determinadas enfermidades. A maneira como utilizamos determinado recorte espacial revela peculiaridades territoriais quanto à exposição a fatores de risco, as condições de acesso aos serviços de saúde, exclusão socioespacial, entre outros fatores determinantes das situações de saúde em grupos sociais (SANTOS, 2007; FARIA; BERTOLOZZI, 2009).

Para Czeresnia e Ribeiro (2000), as contribuiç̧̃̃es de Milton Santos são uma referência relevante para analisar a relação entre espaço e doença, pois permitem compreender a sua produção e dispersão como o resultado da organização social do espaço.

O presente estudo, de abordagem qualitativa, utiliza dados secundários oficiais coletados junto a órgãos de governo, como a Secretaria da Saúde do Rio Grande do Sul (SES-RS), o Ministério da Agricultura, Pecuária e Abastecimento (MAPA), o Instituto Brasileiro de Geografia e Estatística (IBGE), e o Ministério 
do Trabalho e Emprego, através da Relação Anual de Informações Sociais (RAIS) de 2018. Os dados foram inicialmente organizados e sistematizados em planilhas, e após análise prévia, foram georreferenciados através do software QGIS, com a posterior elaboração de mapa temático. Os dados relativos à dispersão da pandemia da Covid-19 na região foram coletados no período de 20 de março a 17 de julho de 2020. De forma complementar, também foram utilizadas para análise reportagens do jornal Gazeta do Sul, de Santa Cruz do Sul, e Informativo do Vale, A Hora e Independente, de Lajeado.

O artigo está estruturado em três seções. Na primeira faz-se uma breve caracterização socioespacial do território da região dos Vales do Taquari e Rio Pardo. Na segunda, apresenta-se o padrão espacial da dispersão territorial da Covid-19 na região dos Vales, e o papel que o funcionamento da rede urbana regional, a dinâmica urbana das cidades médias e a divisão territorial do trabalho regional, tiveram nessa expansão do vírus no território regional e, por fim, apresentam-se as considerações finais deste trabalho.

\section{BREVE CARACTERIZAÇÃO DA REGIÃO DOS VALES E SUA REDE URBANA}

A região dos Vales está localizada na zona Centro Oriental do Estado do Rio Grande do Sul, e seu território corresponde aos territórios contíguos das regiões dos Conselhos Regionais de Desenvolvimento (Coredes) do Vale do Rio Pardo e do Vale do Taquari, que por sua vez integram a Região Funcional de Planejamento 02, instituída pelo Governo Estadual.

De acordo com FEE (2018), a região possuía em 2018 a população total de 806.942 habitantes, equivalente a 7,09\% da população do Estado. Entre os 59 municípios e cidades que integram a região, destacam-se as cidades médias de Santa Cruz do Sul e Lajeado, como os maiores e principais centros urbanos regionais, cada um com, respectivamente, 130.002 e 88.026 habitantes, segundo estimativa populacional do IBGE (2019).

Na região dos Vales a maior parte dos municípios apresenta uma população total com menos de 20 mil habitantes, havendo em muitos deles, especialmente entre os municípios com menos de 10 mil habitantes o predomínio da população rural. Todavia, no conjunto da região a taxa de urbanização se

\footnotetext{
${ }^{1}$ No estado do Rio Grande do Sul, criou-se em 2006 uma regionalização para fins de planejamento territorial, na qual os municípios e as regiões dos Conselhos Regionais de Desenvolvimento - Coredes, foram agrupados em 09 Regiões Funcionais de Planejamento. Esta regionalização, proposta pela Secretaria Estadual de Planejamento, através do Estudo RUMOS 2015, tem como base para a definição das regiões os critérios de homogeneidade econômica, ambiental e social e variáveis relacionadas à identificação das polarizações de emprego, dos deslocamentos por tipo de transporte, da hierarquia urbana, da organização da rede de serviços de saúde e educação superior, entre outros (SEPLAG, DEPLAN, 2015).
} 
intensificou a partir do início do século XXI, sendo que em Lajeado 99,6\% da população é urbana e, em Santa Cruz do Sul, esse percentual alcança 88,9\% (IBGE, 2010).

A estrutura da rede urbana regional é comandada pelas cidades médias de Lajeado e Santa Cruz do Sul, que atuando como Capitais Regionais C na hierarquia urbana, polarizam, centralizam e influenciam, respectivamente, os territórios das regiões do Vale do Taquari e do Vale do Rio Pardo (IBGE, 2020). Essas cidades médias exercem a centralidade e a capacidade de gestão territorial nos espaços regionais onde estão localizadas, através das suas funções administrativas e econômicas. Elas também intermediam fluxos de natureza diversa (pessoas, produtos, mercadorias, insumos, capitais, informações, etc.) que circulam entre as áreas rurais e cidades pequenas, que constituem sua região de influência, e a metrópole de Porto Alegre da qual também experimentam a influência, no contexto da rede urbana estadual.

A crescente especialização e qualificação de alguns serviços oferecidos por essas duas cidades médias como educação superior, saúde, tecnologia e logística tem também atraído empresas e usuários da região metropolitana, intensificando assim os fluxos e as interações entre esses espaços.

As cidades de Encantado e de Venâncio Aires estão classificadas na rede urbana regional, um nível abaixo, como Centros Subregionais B, e apresentam economias urbanas complementares exercendo igualmente, relativa centralidade nas respectivas regiões do Vale do Taquari e Vale do Rio Pardo. Já as cidades de e Sobradinho, Arroio do Tigre, Candelária e Arvorezinha, além da de Teutônia classificam-se como Centros de Zona, exercendo centralidade nos municípios que lhe são contíguos e nas microrregiões onde estão localizadas (IBGE, 2020).²

A economia regional tem forte dependência da produção agropecuária. Em termos de sua produção rural e estrutura fundiária, a região dos Vales pode ser dividida em três zonas distintas. A primeira, referese à parte central e norte do Vale do Rio Pardo, caracterizada por uma estrutura fundiária formada por pequenas propriedades rurais, vinculadas à agricultura familiar, e pela produção de tabaco e milho. A segunda, refere-se à parte sul do Vale do Rio Pardo, que conta com a presença de médias e grandes propriedades rurais, que tem se especializado nas produções de arroz e soja, na criação de gado bovino, e na silvicultura. A terceira, refere-se a região do Vale do Taquari, com a presença de pequenas propriedades rurais, vinculadas à agricultura familiar, cuja produção principal é constituída pela criação de frangos, suínos e produção de leite.

\footnotetext{
2 O IBGE em seu estudo Regiões de Influência das Cidades (REGIC), de 2018 definir essa classificação hierárquica entre os centros urbanos, levando em consideração as redes de interação que conectam as cidades - estas, vistas como centros de gestão do território, como nós principais da rede e da suas respectivas regiões de influência (IBGE, 2020).
} 
A economia urbana apoia-se fortemente no beneficiamento agroindustrial desses produtos primários, com a presença marcante de subsidiárias multinacionais, notadamente nas cidades de Santa Cruz do Sul e Lajeado. Essas duas cidades desempenham, respectivamente, importante papel nos complexos agroindustriais do tabaco e da carne de frango e suíno instalados na região, respondendo por importante participação na produção e exportação nacional, e estando verticalmente integradas ao mercado global desses produtos.

Destacam-se também nessas duas cidades médias: atividades econômicas de empresas e cooperativas locais ligadas aos setores de alimentos; metalmecânica; metalurgia; artefatos de borracha; empresas e instituições privadas relacionadas ao desenvolvimento do comércio atacadista e varejista; serviços especializados, com destaque para saúde e educação superior; e atividades relacionadas ao setor público. Nestas cidades há inúmeras repartições de diversos órgãos públicos federais e estaduais dos poderes executivo e judiciário, que consolidam essas cidades. A busca por estes serviços, evidenciada por meio dos fluxos pendulares para trabalho e estudo, para compra de produtos no comércio atacadista e varejista, e para atendimento especializado de saúde, foi fortalecendo estas cidades enquanto importantes centralidades no âmbito da região dos Vales.

Por tais características, essas cidades médias tornaram-se o lócus do surgimento dos casos da Covid-19 na região, bem como, foram os centros difusores do vírus no território regional.

\section{PADRÃO ESPACIAL DA DIFUSÃO TERRITORIAL DA COVID-19 NA REGIÃO DOS VALES-RS}

Os dados sobre a epidemia da Covid-19 no Rio Grande do Sul, divulgados pela Secretaria Estadual da Saúde, no período 20 de março a 17 de julho de 2020, permitem observar que a pandemia da Covid-19 tem se difundido pelo território estadual apresentando um padrão espacial caracterizado pela difusão do vírus a partir de Porto Alegre e região metropolitana em direção ao interior do estado. Esse padrão espacial da difusão da Covid-19 segue basicamente dois elementos espaciais: os principais eixos rodoviários do Estado e as cidades, em especial as cidades médias, que essas estradas conectam.

A dispersão territorial do vírus segue a estrutura de organização e a dinâmica de funcionamento da rede urbana estadual, partindo da metrópole Porto Alegre e de sua região metropolitana segue para o interior do território pelas rodovias principais em direção às cidades médias, inicialmente aquelas localizadas nas regiões perimetropolitanas, e em seguida para as cidades médias e cidades pequenas localizadas em regiões mais distantes da metrópole.

As cidades médias definem-se sobretudo por sua particular posição no sistema de redes de cidades e por desempenhar uma série de funções de intermediação. Em termos gerais, pode-se conceituar uma 
cidade média ou intermediária como um centro de interação social, econômica e cultural, ou também um centro de bens e serviços mais ou menos especializados para um conjunto da população que supera os limites de seu próprio município, por ser um nó de interação territorial através das infraestruturas de transporte e informação que articulam redes e escala regional, nacional ou internacional (BELLET; LLOP, 2004 apud LLOP; ÚSON, 2012). São cidades articuladoras de diversos tipos de fluxos, materiais e imateriais, que estruturam e organizam o território da região (CORRÊA, 1989). Relacionam-se também às suas funções e, principalmente, ao papel que desempenham na rede urbana regional, nacional e internacional (BRANCO, 2006).

As cidades médias, além de centros urbanos urbanos populosos, são importantes polos econômicos regionais, e como tal concentram a maior parte das empresas, empregos, atividades comerciais e serviços públicos e privados especializados existentes nas respectivas regiões. Assim, atraem fluxos pendulares diários de trabalhadores, estudantes, produtores rurais e consumidores dos municípios das regiões onde essas cidades estão localizadas.

A propagação do vírus pode ocorrer por situações distintas, através do contato entre pessoas de uma mesma cidade, pelo fluxo de pessoas entre cidades próximas, ou, como ocorreu inicialmente, por fluxos de pessoas que regressaram de viagem turística ou de trabalho de outros países também atingidos pela pandemia. Na região dos Vales, os primeiros casos confirmados, no início de março, foram de pessoas que retornavam de viagens à Europa e de um cruzeiro marítimo pela costa brasileira, no caso de Lajeado e Estrela, e de viagens ao litoral catarinense, no caso de Santa Cruz do Sul. Ao final de março, o Estado declarou a situação de transmissão comunitária no estado (GOVERNO DO ESTADO DO RIO GRANDE DO SUL, 2020).

Observando a região dos Vales, no período analisado, constatou-se uma desigual quantidade de infectados com o novo Coronavírus SARS-Cov-2 bem como uma distinta dinâmica de dispersão da pandemia entre os territórios das regiões do Vale do Rio Pardo e do Vale do Taquari. Essa desigual intensidade nos casos e na dinâmica espacial de dispersão está relacionada às qualidades particulares inerentes a história de cada cidade (WELTER, 2008), às diferentes estruturas econômicas, divisões territoriais do trabalho e particulares configurações espaciais, em termos de proximidade, acessibilidade e interação entre as cidades que integram os segmentos da rede urbana existentes em cada uma dessas regiões.

Na região do Vale do Taquari houve uma maior contaminação entre a população dos seus municípios, principalmente em trabalhadores empregados em frigoríficos do município de Lajeado, identificados como focos de infecção da Covid-19. Por conta disso, a partir de Lajeado, houve também uma maior propagação 


\section{Gestãoe \\ Desenvolvimento}

e-ISSN: 2446-6875

p-ISSN: $1807-5436$

do vírus pelos municípios próximos. Algumas características da região podem ter contribuído para esta realidade.

A Figura 1 apresenta um mapa que sobrepõe no espaço geográfico a produção pecuária municipal de rebanhos de bovinos, suínos e de galináceos, conforme dados da Produção Pecuária Municipal (IBGE, 2018); a localização dos frigoríficos de abate de aves, de suínos, e de bovinos, e unidades de beneficiamento de carne e produtos cárneos, conforme dados do Ministério da Agricultura, Pecuária e Abastecimento (MAPA, 2020); e o número de casos confirmados de Covid-19, por município, até o dia 17 de julho de 2020, conforme dados da Secretaria de Saúde do Rio Grande do Sul (SES-RS, 2020b).

Figura 1 - Produção pecuária municipal, presença de frigoríficos e casos de Covid-19 (17/07/2020) nos municípios da Região dos Vales-RS

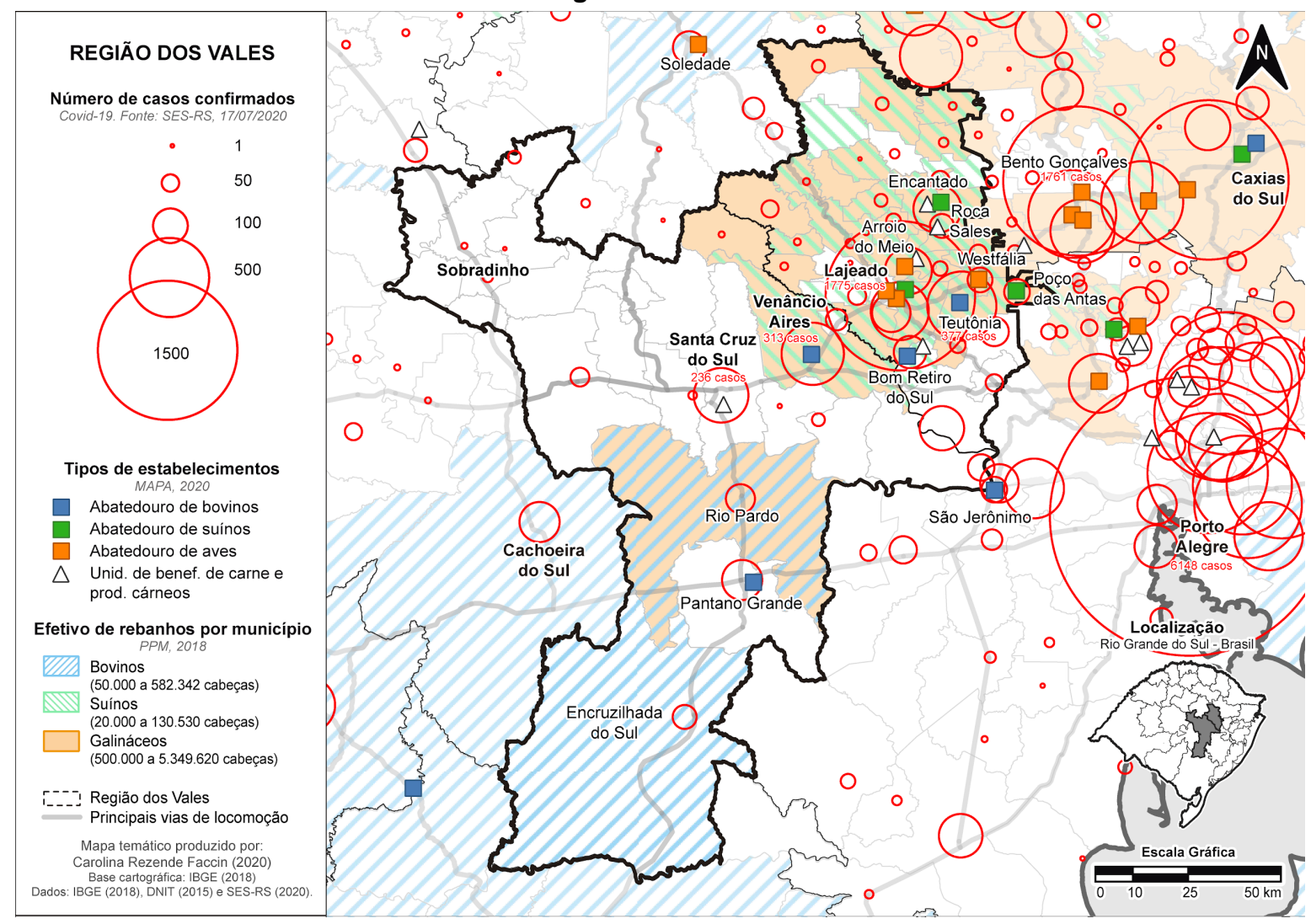

Elaborado por Carolina Rezende Faccin, a partir de MAPA (2020), IBGE (2018) e SES-RS (2020b).

Na região, há presença de 15 frigoríficos e unidades de beneficiamento de produtos cárneos, sendo que 12 deles estão no Vale do Taquari. Desde o final dos anos quarenta, a produção de carnes realizada 
nesta região ocorre através do processo de integração dos agricultores familiares à agroindústria de processamento de carnes.

A partir dos anos noventa, muitos frigoríficos no Estado do Rio Grande do Sul, incluindo alguns da região do Vale do Taquari, vão se adequar às normas do concorrido mercado internacional e iniciam a exportação de seus produtos. Nesse período ocorre também o processo de concentração de capital nesse setor produtivo, com a aquisição total ou parcial de empresas e cooperativas locais, por parte de grandes grupos nacionais e internacionais, como BRF e JBS. No século XXI, empreendimentos focados nas commodities do agronegócio para exportação foram impulsionados e fortalecidos (DELGADO, 2012). Como resultado na crescente expansão desse setor produtivo, com vistas para o mercado externo, foi inaugurada uma planta frigorífica em Poço das Antas, em 2012, e, mais recentemente, em dezembro de 2019, um complexo avícola foi inaugurado em Arroio do Meio.

Estas informações tornam-se relevantes em meio ao crescente aumento de casos confirmados de Covid-19 na região dos Vales e, principalmente naquelas cidades com presença de frigoríficos. O município de Lajeado, até 17 de julho de 2020, contava com 1.775 casos confirmados do vírus, sendo que, entre os dias 22 de maio e 16 de junho, foi o município com o maior número de casos do Estado. Esse aumento no número de casos se justifica pela disseminação do vírus através dos dois frigoríficos presentes na cidade, quando estes se tornaram o principal foco de contágio (CHAPARINI, 2020). Conforme Medina (2020), até o dia 22 de maio, 530 pessoas, dos 840 dos infectados em Lajeado, eram funcionários dos frigoríficos. Juntos, esses frigoríficos empregam mais de 4.982 funcionários que atuam nos setores de abate de aves, abate de suínos e fabricação de produtos da carne (RAIS, 2018). Tal situação levou à interdição por 15 dias, por parte da justiça estadual, desses dois frigoríficos, devido ao alto índice de funcionários que testaram positivo para a Covid-1933 (HAUTRIVE, 2020).

Observa-se que a difusão do vírus entre as cidades da região do Vale do Taquari está bastante atrelada à estrutura da rede urbana e aos fluxos de trabalhadores no âmbito da cadeia produtiva da produção de carne, tendo em vista que a economia regional é composta por uma intensa rede de divisão de atividades, realizada pelas empresas, entre as cidades. Por exemplo, em um município é produzido a ração, em outro são criados os animais e em outro há o frigorífico de abate e processamento de carnes. É o caso da Companhia Minuano de Alimentos, cujo frigorífico de abate de aves está localizado em Lajeado,

\footnotetext{
${ }^{3}$ O aumento do número de casos de Covid-19, tendo como foco de disseminação os frigoríficos, se repetiu nos municípios de Bento Gonçalves, Garibaldi, Passo Fundo, Marau, e até mesmo em outros países como os Estados Unidos, Alemanha e Canadá. O que ainda se observa, é que os casos confirmados se concentram em unidades de abates de aves, como foi o caso da JBS em Passo Fundo, e da Minuano e BRF em Lajeado (MAPA, 2020; RAIS, 2018; HECK et al., 2020; LECLERC et al., 2020).
} 
a fábrica de rações e a unidade de beneficiamento de produtos cárneos, em Arroio do Meio, o incubatório de aves em Estrela e aviários em Estrela e Bom Retiro do Sul (RAIS, 2018; MAPA, 2020).

A proximidade entre as cidades do Vale do Taquari contribui para o deslocamento pendular diário de pessoas para trabalhar nestes locais. Como a conectividade entre elas é facilitada pela acessibilidade e proximidade espacial, muitas pessoas residem em uma cidade e trabalham em outra, tornando-se importantes vetores de transmissão do vírus entre cidades. Por conta dessa proximidade espacial, os municípios contíguos à Lajeado também apresentaram um aumento do número de casos durante o mesmo período dos dias 22 de maio e 16 de junho. São eles: Arroio do Meio (que apresentava 178 casos totais, no dia 17 de julho), Cruzeiro do Sul (com 120 casos) e Estrela (com 267 casos) (SES-RS, 2020).

Entender o funcionamento do ambiente de trabalho dos funcionários da linha de produção dos frigoríficos pode ajudar a explicar a rápida e fácil transmissão do vírus nesses locais. Como explica Barzotto (2013), na etapa de evisceração, o ambiente é úmido, com variações extremas de temperatura, e os trabalhadores ficam próximos uns dos outros, cerca de 01 metro de distância separados uns dos outros, em contato o dia todo com água e resíduos. Já a linha de produção é o maior setor do frigorífico, local úmido e cuja temperatura não deve ultrapassar $12^{\circ} \mathrm{C}$ (BRASIL, 1998).

A pesquisa de Günther et al. (2020), que investigou como ocorreu a disseminação do vírus e o início do surto de SARS-Cov-2 na maior planta de processamento de carne na Alemanha, revelou que a transmissão não depende apenas de proximidade social dos trabalhadores, mas de vários fatores relacionados às condições do ambiente de trabalho. $\mathrm{O}$ ar circulando a $10^{\circ} \mathrm{C}$, e sendo constantemente reciclado, sem circulação de ar fresco, somadas ao trabalho físico extenuante, teriam facilitado a propagação do vírus para um raio de oito metros ou mais, dentro do frigorífico. Assim, a proximidade entre os trabalhadores dos frigoríficos, o ambiente frio e úmido, com consequente presença de gotículas no ar, e o grande número de funcionários em um mesmo ambiente, tornam o ambiente propício para propagação do vírus.

Já na região do Vale do Rio Pardo, embora também haja a presença de alguns frigoríficos de abate de gado bovino, essa dinâmica de dispersão da Covid-19 foi distinta. Nessa região, a economia regional está estruturada sobretudo na cadeia produtiva do tabaco em folha, cuja divisão territorial do trabalho apresenta-se menos complexa, refletindo em uma rede urbana mais simples do ponto de vista do seu funcionamento e da dinâmica dos fluxos. Nela, as cidades de Santa Cruz do Sul e Venâncio Aires concentram a maior parte das indústrias nas quais os agricultores familiares entregam o tabaco, produzido nas pequenas propriedades rurais localizadas nos municípios da região. Tais cidades também concentram as empresas de serviços e os postos de emprego vinculados ao setor. Atualmente, são aproximadamente 9 mil trabalhadores, a maior parte deles, em torno de 7 mil, são temporários, contratados no período da safra (GAZETA DO SUL, 12 fev. 2020). 
Todavia, o processo de processamento industrial do tabaco difere bastante do praticado nos frigoríficos. $O$ ambiente nas linhas de produção das usinas de tabaco não apresenta grandes variações de temperatura, e os trabalhadores ficam mais distantes uns dos outros. Além disso, medidas importantes têm sido tomadas por algumas empresas desse setor como suspensão temporária das atividades, redução temporária do número de empregados e uso obrigatório de equipamento de proteção individual, no sentido de reduzir esse risco de contaminação e propagação da Covid-19.

A distribuição territorial do vírus na região do Vale do Rio Pardo apresentou atéo dia 17 de julho de 2020 uma maior concentração dos casos nas cidades de Santa Cruz do Sul, com 236 casos, e de Venâncio Aires, com 313 casos. Em Santa Cruz do Sul ocorreu um aumento gradativo no número de casos, ocasionados pelo fluxo semanal de pessoas que se deslocam entre a cidade e a região metropolitana de Porto Alegre, pelas recorrentes aglomerações de pessoas na área central da cidade, onde se localizam grande parte dos estabelecimentos comerciais e de serviços, e pelo crescente relaxamento no distanciamento social. A cidade exerce forte centralidade regional atraindo fluxos pendulares dos municípios vizinhos para trabalho, para estudo e para o comércio e serviços especializados, como são os casos dos deslocamentos diários originados nos municípios de Rio Pardo, Pantano Grande e Vera Cruz. Tal dinâmica de interação espacial contribuiu para a difusão da pandemia entre esses municípios da região. Em Rio Pardo, até 17 de julho de 2020, foram totalizados 70 casos e em Pantano Grande, 132 casos. Já no município de Venâncio Aires a pandemia tem se difundido principalmente através dos deslocamentos pendulares de pessoas que se deslocam da cidade para trabalhar em frigoríficos, em Lajeado no Vale do Taquari.

\section{CONSIDERAÇÕES FINAIS}

No atual contexto, o surgimento e a rápida difusão global da pandemia da Covid-19 estão associados às condições do atual conteúdo técnico-científico-informacional do espaço geográfico, que acelera fluxos diversos, aproxima e articula regiões e lugares, facilitando a circulação do vírus diante da globalização da economia.

O fluxo de difusão do vírus no espaço mundial tem revelado padrões espaciais de dispersão, intensidades de contágio e reflexos sociais e econômicos distintos nos diferentes territórios nacionais e em suas regiões. Resultado não apenas do desigual conteúdo das estruturas sanitárias e de saúde que dispõem, mas também em razão das dinâmicas sociais e econômicas neles existentes, do modo como o trabalho está territorialmente organizado e distribuído, da estrutura, abrangência e integração da rede urbana e da efetividade das políticas públicas de prevenção, controle e mitigação adotadas em cada 
território. Ou seja, os territórios e os seus usos importam tanto na análise dessa pandemia, quanto na busca de sua superação.

Observamos que a dinâmica de dispersão territorial da Covid-19 na região dos Vales e em suas cidades médias, de Santa Cruz do Sul e Lajeado, no Rio Grande do Sul apresenta características semelhantes ao verificado em outras regiões e cidades no Brasil e no exterior, mas também revela particularidades, inclusive entre as sub-regiões que the constituem, relacionadas aos usos do território. 0 padrão espacial da dispersão territorial da Covid-19 mostrou-se até o momento, diferente entre as sub-regiões do Vale do Rio Pardo e do Vale do Taquari. Essa diferença está fortemente associada à divisão territorial do trabalho regional e à configuração espacial e à dinâmica dos fluxos da rede urbana regional, existente em cada uma das sub-regiões. A presença de 15 frigoríficos e unidades de beneficiamento de produtos cárneos, 12 deles no Vale do Taquari, com condições ambientais de grande umidade e variação de temperatura em linhas de produção com pouco distanciamento entre o expressivo número de trabalhadores envolvidos na atividade industrial da cadeia produtiva da carne de aves e suínos tem sido uma das variáveis que explicam o grande número de casos da doença nessa sub-região. A outra variável que tem contribuído significativamente para essa maior intensidade e difusão territorial da Covid-19 tem sido a estrutura regionalizada de produção dessa cadeia produtiva, envolvendo intensos fluxos não apenas de insumos e produtos, mas também de pessoas, que residem em uma cidade e se deslocam para trabalhar em outra, contribuindo assim para que o vírus se difundisse mais intensamente pelas cidades dessa região. Dentre elas, destaca-se Lajeado, dada a maior concentração de frigoríficos e de população, e que permaneceu por algumas semanas, entre maio e junho de 2020, como o município com o maior número de casos registrados da Covid-19 no estado.

No Vale do Rio Pardo, a dispersão da Covid-19 foi distinta, tendo em vista que a economia regional está fortemente estruturada na cadeia produtiva do tabaco, cuja dinâmica de produção envolve uma divisão territorial do trabalho mais simples, com grande parte das estruturas produtivas concentradas em Santa Cruz do Sul e, secundariamente, em Venâncio Aires, resultando em menor intensidade nos fluxos urbanos entre as cidades dessa sub-região.

Tais características econômicas e sociais do modo como a produção e o trabalho se organiza e se distribui no território, particularizam os territórios dessas duas sub-regiões, promovendo distintas dinâmicas na estrutura urbana regional. Os resultados aqui analisados não são definitivos. A pandemia ainda avança na região dos Vales e em suas cidades médias, assim como nas demais regiões e cidades do estado, do País e dos demais países. Muitas são as incertezas, as inseguranças. Variados são e serão os seus reflexos e impactos nos diferentes territórios, reforçando nossa crença de que também para a 


\section{Gestãoe \\ Desenvolvimento}

e-ISSN: 2446-6875

p-ISSN: $1807-5436$

construção de saídas para essa crise sanitária e econômica, as particularidades e os ativos territoriais precisam ser considerados. Os territórios importam.

\section{REFERÊNCIAS}

BRANCO, Maria Luisa Castello. As cidades médias no Brasil. In: SPÓSITO, Eliseu Savério; SPÓSITO, Maria Encarnação Beltrão; SOBARZO, Oscar (orgs.). Cidades médias: produção do espaço urbano regional. São Paulo: Expressão Popular, 2006. p. 245-277.

BRASIL. Ministério da Agricultura e do Abastecimento. Portaria n. 210 de 10 de novembro de 1998. Aprovar o Regulamento Técnico da Inspeção Tecnológica e Higiênico-Sanitária de Carne de Aves. Diário Oficial da União. Ministério da Agricultura e do Abastecimento/Secretaria de Defesa Agropecuária, Brasília, 26 nov. 1998, Seção 1, p. 226.

Brasil confirma primeiro caso da doença. Ministério da Saúde, 26 fev. 2020. Disponível em: <https://www.saude.gov.br/noticias/agencia-saude/46435-brasil-confirma-primeiro-caso-de-novo-coronavirus>. Acesso em: 14 jul. 2020.

CZERESNIA, Dina; RIBEIRO, Adriana Maria. O Conceito de Espaço em Epidemiologia: uma interpretação histórica e epistemológica. Cadernos de Saúde Pública, Rio de Janeiro, v. 16, n. 3, p. 595-613, 2000.

CHAPARINI, Matheus. Frigoríficos são principal foco de contágios na região. Grupo A Hora, 25 de abr. 2020. Disponivel em: <https://grupoahora.net.br/conteudos/2020/04/25/frigorificos-sao-principal-foco-de-contagios-na-regiao/>. Acesso em: 28 mai. 2020.

CORRÊA, Roberto Lobato. A rede urbana. São Paulo: Editora Ática, 1989.

DELGADO, G. Do capital financeiro na agricultura à economia do agronegócio: mudanças cíclicas em meio século (1965-2012). Porto Alegre: Editora da UFRGS, 2012.

FARIA, Rivaldo Mauro; BORTOLOZZI, Arlêude. Espaço, Território e Saúde: Contribuições de Milton Santos para o Tema da Geografia da Saúde no Brasil. RA'E GA - 0 Espaço Geográfico em Análise, Curitiba, v. 17, n. 3, pp. 31-42, jan./dez. 2009.

INDEPENDENTE. Lajeado lidera o ranking dos municípios com pior desempenho em isolamento social. Grupo Independente, Lajeado, 29 jul. 2020. Disponível em: <https://independente.com.br/regiao-de-lajeado-lidera-ranking-dos-municipios-com-pior-desempenho-de-isolamento-social/>. Acesso em: 30 jul. 2020. 


\section{Gestãoe \\ Desenvolvimento}

e-ISSN: 2446-6875

p-ISSN: $1807-5436$

INSTITUTO BRASILEIRO DE GEOGRAFIA E ESTATÍSTICA - IBGE. Censo demográfico de 2010. Rio de Janeiro: IBGE, 2010.

Estimativas da população total - 2019. Rio de Janeiro: IBGE, 2019. Disponível em: <https:// www.ibge.gov.br/estatisticas/sociais/populacao/9103-estimativas-de-populacao.html?=\&t=downloads>. Acesso em: 21 jul. 2020.

Pesquisa da Pecuária Municipal - PPM: Tabela 3939 - Efetivo dos rebanhos, por tipo de rebanho. Rio de Janeiro: IBGE, 2018. Disponivel em: <https://sidra.ibge.gov.br/tabela/3939>. Acesso em: 20 mai. 2020 .

Região de Influência das Cidades - REGIC 2018. Rio de Janeiro: IBGE, 2020.

GOVERNO DO ESTADO DO RIO GRANDE DO SUL. RS confirma transmissão comunitária do novo coronavírus. Palácio Piratini, Porto Alegre, 20 mar. 2020. Disponível em: <https://www.estado.rs.gov.br/ rs-confirma-transmissao-comunitaria-do-novo-coronavirus>. Acesso em: 29 jul. 2020.

GUENTHER, T. et al. Investigation of a superspreading event preceding the largest meat processing plant-related SARS-Coronavirus 2 outbreak in Germany. Rochester, NY. Social Science Research Network, 17 jul. 2020. Disponivel em: <https://papers.ssrn.com/abstract=3654517>. Acesso em: 29 jul. 2020

HAUTRIVE, Gabriela. BRF retoma produção com mais de 50\% dos funcionários. Grupo Independente, Lajeado, 27 mai. 2020. Disponível em: <https://independente.com.br/brf-retoma-producao-com-mais-de-50-dos-funcionarios/>. Acesso em: 23 jul. 2020.

HECK, F. M.; NASCIMENTO JÚNIOR, L.; RUIZ, R. C.; MENEGON, F. A. Os territórios da degradação do trabaIho na Região Sul e o arranjo organizado a partir da COVID-19: A centralidade dos frigoríficos na difusão espacial da doença. Metodologias e Aprendizado, Blumenau, v. 3, 2020. Disponível em: <http://publicacoes.ifc.edu.br/index.php/metapre/article/view/1332>. Acesso em: 30 jul. 2020.

LECLERC, Q. J. et al. What settings have been linked to SARS-CoV-2 transmission clusters? Wellcome Open Research, Londres, v. 5, p. 83, 5 jun. 2020. Disponível em: <https://wellcomeopenresearch.org/articles/5-83>. Acesso em: 30 jul. 2020.

LLOP, Josep. M.; USÓN, Ezequiel. Ciudades intermedias: dimensiones y definiciones. Lleida: Editorial Milenio, 2012.

MINISTÉRIO DA AGRICULTURA, PECUÁRIA E ABASTECIMENTO - MAPA. Registro dos estabelecimentos do setor de produção de carne. Brasília: MAPA, 2020. Disponível em: <http://sigsif.agricultura.gov.br/ 


\section{Gestãoe \\ Desenvolvimento}

e-ISSN: 2446-6875

p-ISSN: 1807-5436

sigsif_cons/\%21ap_estabelec_nacional_rep?p_relatorio=estabelecimentos.rdf $>$. Acesso em: 27 mai. 2020.

MEDINA, Maiara. Mais de 60\% dos infectados em Lajeado são funcionários de frigoríficos, aponta prefeitura. RBS TV, Porto Alegre, 22 mai. 2020. Disponível em: <https://g1.globo.com/rs/rio-grande-do-sul/ noticia/2020/05/22/mais-de-60percent-dos-infectados-em-lajeado-sao-funcionarios-de-frigorificos-aponta-prefeitura.ghtml>. Acesso em: 23 jul. 2020.

RELAÇÃO ANUAL DE INFORMAÇÕES SOCIAIS - RAIS. Número de vínculos ativos por estabelecimento. Brasília: Ministério da Economia, 2018. Disponível em: <http://bi.mte.gov.br/bgcaged/caged_rais_vinculo_id/login.php>. Acesso em: 21 jul. 2020.

RIBEIRO, Natalia. Estrela e lajeado confirmam os primeiros pacientes infectados com coronavírus no Vale. Grupo Independente, 21 mar. 2020. Disponivel em: <https://independente.com.br/estrela-e-lajeado-confirmam-os-primeiros-pacientes-infectados-com-coronavirus-no-vale-do-taquari/>. Acesso em: 14 jul. 2020.

SANTOS, Milton. A Natureza do espaço: Técnica e tempo. São Paulo: Hucitec, 2006.

SECRETARIA DO ESTADO DE SAÚDE DO RIO GRANDE DO SUL - SES-RS. Confirmado o primeiro caso de novo coronavírus no Rio Grande do Sul. Secretaria do Estado de Saúde do Rio Grande do Sul, 2020a. Disponivel em: <https://saude.rs.gov.br/confirmado-o-primeiro-caso-de-novo-coronavirus-no-rio-grande-do-sul>. Acesso em: 14 jul. 2020a.

. Painel Coronavírus RS. Secretaria do Estado de Saúde do Rio Grande do Sul, 2020b. Disponível em: <https://ti.saude.rs.gov.br/covid19/>. Acesso em: 23 jul. 2020b.

SECRETARIA DE PLANEJAMENTO, GOVERNANÇA E GESTÃO - SEPLAG; DEPARTAMENTO DE PLANEJAMENTO GOVERNAMENTAL - DEPLAN. Perfis Socioeconômicos Regiões Funcionais de Planejamento. Porto Alegre: SEPLAG/DEPLAN, 2015.

WELTER, R. T.; MORAES, M. C.; MAFRA, W. J.; SANTOS, N. Estratégia do Desenvolvimento Urbano como Fator Determinante para o Desenvolvimento Industrial Sustentável. Revista Gestão e Desenvolvimento, v. 5, n. 2, p. 63-69, 2008.

WORD HEALTH ORGANIZATION - WHO. Coronavirus 2019 - Situation report 51 - 11 march 2020. World Health Organization, 2020. Disponivel em: <https://www.who.int/emergencies/diseases/novel-coronavirus-2019/situation-reports/>. Acesso em: 21 jul. 2020. 